\title{
Depletion of endogenous germ cells in tree shrews in preparation for spermatogonial transplantation
}

\author{
TINGTING LIU ${ }^{1,2^{*}}$, YING GUO ${ }^{1,2^{*}}$, LANZHEN YAN ${ }^{2,3}$, BIN SUN $^{2}$, PING ZHENG $^{2,3}$ and XUDONG ZHAO ${ }^{2,3}$ \\ ${ }^{1}$ School of Life Science, Anhui University, Hefei, Anhui 230039; \\ ${ }^{2}$ Key Laboratory of Animal Models and Human Disease Mechanisms; ${ }^{3}$ Kunming Primate Research Center, \\ Kunming Institute of Zoology, Chinese Academy of Sciences, Kunming, Yunnan 650223, P.R. China
}

Received March 31, 2016; Accepted March 17, 2017

DOI: $10.3892 /$ etm.2017.4767

\begin{abstract}
To achieve successful spermatogonial transplantation, endogenous germ cells must be depleted in recipient animals to allow donor germ cells to colonize efficiently. Busulfan is commonly used for the depletion of endogenous germ cells in recipient males. However, the optimal dose of busulfan is species-specific, and the optimal dose in tree shrews is yet to be determined. The current study aimed to determine the optimal dose of busulfan for effective suppression of endogenous spermatogenesis in tree shrews. Different doses $(15,20,25,30,35,40$ and $45 \mathrm{mg} / \mathrm{kg})$ of busulfan were injected into tree shrews intraperitoneally. Survival rates of the different treatment groups were calculated at 2 weeks and body weights were measured at 4, 6, 8, 10 and 28 weeks post-busulfan treatment. The testes were also removed and weighed at 4, 6, 8, 10 and 28 weeks post-treatment, and the cross and longitude diameters of the testes and diameters of the seminiferous tubules were measured and histologically evaluated. It was observed that there were no significant differences in the survival rates between the $15-35 \mathrm{mg} / \mathrm{kg}$ treatment groups and the control group ( $\mathrm{P}>0.05)$, while the survival rate of the $40 \mathrm{mg} / \mathrm{kg}$ treatment group significantly decreased relative to the control group $(\mathrm{P}<0.05)$ and the survival rate of the $45 \mathrm{mg} / \mathrm{kg}$ treatment group was $0 \%$ ( $\mathrm{P}<0.05 \mathrm{vs}$. control). In addition, the weight and diameters of the testes, diameters of the seminiferous tubules and proportion of normal type tubules in the $40 \mathrm{mg} / \mathrm{kg}$ group significantly decreased over 4-10 weeks relative to the control group $(\mathrm{P}<0.05)$, though gradually recovered with time. At 28 weeks, the recovery
\end{abstract}

Correspondence to: Professor Xudong Zhao, Kunming Primate Research Center, Kunming Institute of Zoology, Chinese Academy of Sciences, 21 Qingsong Road, Kunming, Yunnan 650223, P.R. China

E-mail: zhaoxudong@mail.kiz.ac.cn

${ }^{*}$ Contributed equally

Key words: tree shrew, busulfan, endogenous germ cell, spermatogonial transplantation was significant relative to 4 weeks $(\mathrm{P}<0.05)$. Similarly, histological analysis indicted that recovery of abnormal tubules was delayed in the $40 \mathrm{mg} / \mathrm{kg}$ group relative to the lower dose groups as the $40 \mathrm{mg} / \mathrm{kg}$ dose tree shrews had more tubules with no spermatogenesis compared with the lower dose group at the same time points. These data indicate that a busulfan dose of $40 \mathrm{mg} / \mathrm{kg}$ is optimal for the depletion of endogenous germ cells in tree shrews. This dose led to maximum suppression of endogenous spermatogenesis while maintaining an acceptable survival rate of $>50 \%$ of the lethal dose of busulfan for tree shrews.

\section{Introduction}

Spermatogonial transplantation has a range of applications and may be used for numerous processes, including spermatogenesis (1), the restoration of fertility (2) and the production of transgenic animals (3). Donor spermatogonial stem cells injected into recipient males colonize the seminiferous tubules and lead to donor-derived spermatogenesis $(3,4)$. Donor germ cells compete with endogenous germ cells in the colonization of stem cell niches within recipient males, and thus a relatively larger number of donor germ cells is required for successful colonization $(5,6)$. The efficiency of colonization may be improved by the elimination of endogenous germ cells within recipient males, which promotes the successful colonization of donor spermatogonial stem cells (7).

A number of methods are used for the depletion of endogenous germ cells in spermatogonial transplantation. The most commonly used method involves an injection of busulfan. Busulfan is a DNA-alkylating agent that may deplete germ cells, and has been demonstrated to deplete recipient endogenous germ cells in rodents (8-11). However, the optimal dose of busulfan varies between different species (12).

Tree shrews (Tupaia belangeri) are small mammals that belong to the families Tupaiidae and Ptilocercidae. Their natural habitats are distributed in tropical and subtropical areas, including Thailand, Malaysia, Indonesia and Southwest China (13). Tree shrews are considered to be useful animal models due to their phylogenetically close relationship to primates and possession of the typical characteristics required of experimental animals including small body size, high brain-to-body mass ratio, short reproductive cycle and life 
span, and low-cost of maintenance (14). Tree shrews may be used to establish various human disease models including a virus hepatitis model, carcinoma model, and psychosocial stress model (15-17). More recently, a tree shrew model for spermatogonial transplantation has been established, which may aid in many avenues of biological research such as the study of spermatogenesis, production of transgenic animals, and male infertility therapy.

The optimal dose of busulfan should induce maximal depletion of endogenous germ cells in recipient males while maintaining an acceptable survival rate. No previous systematic studies have defined the optimal dose of busulfan for experimental tree shrews. Therefore, the present study administrated different doses of busulfan to tree shrews, with the aim of identifying the optimal dose.

\section{Materials and methods}

Animals. A total of 120 male tree shrews obtained from the Kunming Primate Research Center (Kunming, China) were used in the present study. The mean age was 6 months and the mean weight was $137 \mathrm{~g}$. The animals were maintained individually in separate cages in a 12-h light-dark cycle and constant room temperature $\left(25-27^{\circ} \mathrm{C}\right.$; relative humidity, $50-70 \%$ ) with ad libitum access to water and food. All animals were treated in accordance with protocols for the use of experimental animals approved by Institutional Animal Care and Use Committee of Kunming Institute of Zoology (Kunming, China), which complied with the Guide for the Care and Use of Laboratory Animals, prior to the use of animals in the current study.

Busulfan treatment. Busulfan was dissolved in dimethyl sulfoxide (DMSO) at a concentration of $18 \mathrm{mg} / \mathrm{ml}$. The solubility of busulfan in water is poor, and thus to prevent precipitation, an equal volume of heated $\left(37^{\circ} \mathrm{C}\right)$ double distilled water was added to the busulfan/DMSO mix prior to injection, yielding a final concentration of $9.0 \mathrm{mg} / \mathrm{ml}$.

The tree shrews were randomly allocated into 7 experimental groups administered with different doses of busulfan as follows: $15 \mathrm{mg} / \mathrm{kg}$ group $(\mathrm{n}=11), 20 \mathrm{mg} / \mathrm{kg}$ group $(\mathrm{n}=15)$, $25 \mathrm{mg} / \mathrm{kg}$ group ( $=14), 30 \mathrm{mg} / \mathrm{kg}$ group ( $=19), 35 \mathrm{mg} / \mathrm{kg}$ group $(\mathrm{n}=18), 40 \mathrm{mg} / \mathrm{kg}$ group $(\mathrm{n}=18)$, and $45 \mathrm{mg} / \mathrm{kg}$ group $(n=10)$, and one control group without busulfan treatment $(n=15)$. All animals were weighed prior to intraperitoneal busulfan injection. The survival rates were calculated at 4 weeks by dividing the number of mortalities after busulfan treatment by the total number of animals in each group. The animals were humanely sacrificed by cervical dislocation if pre-determined humane endpoints were observed, including excessive weight loss, loss of ability to ambulate and inability to reach food or water. A total of 25 tree shrews were sacrificed due to the observation of humane endpoints, including excessive weight loss, loss of ability to ambulate and inability to reach food or water. Tree shrews were anaesthetized using 200 mg/kg ketamine (China Animal Husbandry Industry, Co., Ltd., Beijing, China) via intramuscular injection and sacrificed by cervical dislocation at 4, 6, 8, 10 and 28 weeks after busulfan injection. At each time point, 2-3 tree shrews were sacrificed.
Histology. Following cervical dislocation, the testes were collected and weighed. The longitudinal and cross diameters of testes in each tree shrew were measured with calipers. Testes then were fixed in $4 \%$ paraformaldehyde for $48 \mathrm{~h}$ at room temperature. The testes were transferred to ethanol for dehydration at room temperature using a concentration gradient: $50 \%$ for $1 \mathrm{~h}, 70 \%$ for $1 \mathrm{~h}, 80 \%$ for $1 \mathrm{~h}, 90 \%$ for $1 \mathrm{~h}$, $95 \%$ for $40 \mathrm{~min}, 100 \%$ I for $30 \mathrm{~min}$, and $100 \%$ II for $30 \mathrm{~min}$, followed by treatment with xylene twice at room temperature for $1 \mathrm{~h}$ each to remove the ethanol. Samples were then infiltrated and embedded in paraffin. The paraffin-embedded samples were sectioned with a Leica microtome (Leica Microsystems, Inc., Buffalo Grove, IL, USA) and the resulting sections $(4.5 \mu \mathrm{m})$ were stained with hematoxylin and eosin. Stained sections were observed using an inverted fluorescence microscope (Olympus IX-71; Olympus Corporation, Tokyo, Japan) and images were acquired digitally using CellSens standard software version 1.5 (Olympus Corporation). The diameters of 30 seminiferous tubules were measured at each time point using a light microscope (Olympus CX31; Olympus Corporation). The numbers of different types of tubules were counted and their percentages were calculated.

Statistical analysis. Analyses were performed using SPSS version 13.0 (SPSS, Inc., Chicago IL, USA). Results were analyzed using one-way analysis of variance and a $\chi^{2}$ test and the data were shown in mean \pm standard error of the mean. Differences were considered to be statistically significant when $\mathrm{P}<0.05$.

\section{Results}

Survival rate of busulfan treatment groups. The survival rates of tree shrews at 4 weeks after busulfan treatment $(15,20,25$, $30,35,40$ and $45 \mathrm{mg} / \mathrm{kg}$ ) are depicted in Fig. 1. A busulfan dose of $15-35 \mathrm{mg} / \mathrm{kg}$ had no significant effect on the survival rate of tree shrews ( $\mathrm{P}>0.05$ vs. control), while injection with $40 \mathrm{mg} / \mathrm{kg}$ busulfan significantly decreased survival rate $(\mathrm{P}<0.05$ vs. control), though to a moderate extent $(72 \%$ in $40 \mathrm{mg} / \mathrm{kg}$ busulfan group vs. 100\% in control group). However, $45 \mathrm{mg} / \mathrm{kg}$ busulfan significantly decreased survival rate to $0 \%$ ( $\mathrm{P}<0.05$ vs. control), and thus was deemed to be $100 \%$ lethal. Due to the unacceptably high mortality rate, tree shrews treated with $45 \mathrm{mg} / \mathrm{kg}$ busulfan were omitted from subsequent assays.

Tree shrew body weight is unaffected by busulfan treatment. The body weight of the $40 \mathrm{mg} / \mathrm{kg}$ busulfan-treated tree shrews and untreated controls did not differ significantly $(\mathrm{P}>0.05)$. As depicted in Fig. 2, time-dependent body weight in the $40 \mathrm{mg} / \mathrm{kg}$ group did not differ significantly, relative to the control group $(\mathrm{P}>0.05)$. The $40 \mathrm{mg} / \mathrm{kg}$ group exhibited an acceptable survival rate and there was no significant change in body weight, indicating little toxicity to tree shrews, therefore the current study focused on the $40 \mathrm{mg} / \mathrm{kg}$ group to minimize the suffering of animals.

Change in tree shrew testes weights and diameters following busulfan treatment. The testicular weights of $40 \mathrm{mg} / \mathrm{kg}$ busulfan-treated tree shrews were decreased relative to that 
of untreated tree shrews, indicating that spermatogenesis had been suppressed. In the $40 \mathrm{mg} / \mathrm{kg}$ group, testes weight was significantly reduced between weeks 4 and 10 post-treatment, relative to the control group $(\mathrm{P}<0.05$; Fig. 3$)$. Between weeks 10 and 28 , testicular weight recovered almost to control level (Fig. 3). The cross and longitudinal diameters of testes were also measured in the $40 \mathrm{mg} / \mathrm{kg}$ group. Both diameters were significantly decreased in the $40 \mathrm{mg} / \mathrm{kg}$ group between weeks 4 and $10(\mathrm{P}<0.05)$, though recovered almost to control level by week 28 (Fig. 4).

Histological changes in the tubule diameters. Using histological analysis, it was observed that the diameters of the seminiferous tubules following $40 \mathrm{mg} / \mathrm{kg}$ busulfan treatment were significantly decreased between weeks 4 and 10, relative to the control group $(\mathrm{P}<0.05)$. However, the seminiferous tubule diameter recovered to a level similar to that observed in the control group by week 28 (Fig. 5).

Classification of seminiferous tubules. The seminiferous tubules were classified into three types following busulfan treatment. Fig. 6A represents normal seminiferous tubules with sperm (NS) obtained from untreated controls. The NS tubule has a thick wall and a narrow lumen, and the seminiferous epithelium contains spermatogenic and Sertoli cells. During the process of spermiogenesis, the spermatogenic cells divide into sperm. Fig. 6B represents normal seminiferous tubules without sperm $(\mathrm{N})$ obtained from tree shrews 6 weeks after injection of $20 \mathrm{mg} / \mathrm{kg}$ busulfan. The $\mathrm{N}$ tubules existed in all lower dose treatment groups. The majority of $\mathrm{N}$ tubules exhibited thinner walls following lower doses, $<20 \mathrm{mg} / \mathrm{kg}$, of busulfan treatment. Fig. $6 \mathrm{C}$ represents abnormal seminiferous tubules $(\mathrm{Ab})$ obtained from tree shrews 4 weeks after injection of $40 \mathrm{mg} / \mathrm{kg}$ busulfan. The majority of Ab tubules exhibited further thinning of the tubule walls following the high-dose $(40 \mathrm{mg} / \mathrm{kg})$ busulfan treatment.

Changes in percentages of three tubule types. The percentages of NS, N and Ab tubules in the control and high-dose busulfan treatment groups were subsequently determined. As depicted in Fig. 6D, no NS tubules were observed in the testes between 4-8 weeks after $40 \mathrm{mg} / \mathrm{kg}$ busulfan treatment. However, tubule regeneration was apparent by week 10 with NS, and $\mathrm{Ab}$ exhibited 19.2, 50 and $29.8 \%$ regeneration, respectively and by week 28 , no Ab tubules were observed in the testes of the $40 \mathrm{mg} / \mathrm{kg}$ group (Fig. 6D).

Comparison of different tubule types between lower and higher dose groups. A comparison between the different doses of busulfan indicated that the number of Ab tubules increased with increasing doses of busulfan (Fig. 7). Between weeks 4 and 6 post-treatment, tree shrews in the $40 \mathrm{mg} / \mathrm{kg}$ group exhibited an increased number of non-spermatogenic tubules when compared to groups treated with $15-35 \mathrm{mg} / \mathrm{kg}$ busulfan at each time point. At 4 weeks post-treatment, tree shrews in the groups treated with $\leq 20 \mathrm{mg} / \mathrm{kg}$ group exhibited only $\mathrm{N}$ and NS tubules, and tree shrews in the $25 \mathrm{mg} / \mathrm{kg}$ group exhibited a small number of $\mathrm{Ab}$ tubules. Results for the 20 and $25 \mathrm{mg} / \mathrm{kg}$ groups are representative of all lower dose treatment groups. By contrast, tree shrews in the $40 \mathrm{mg} / \mathrm{kg}$ group exhibited only

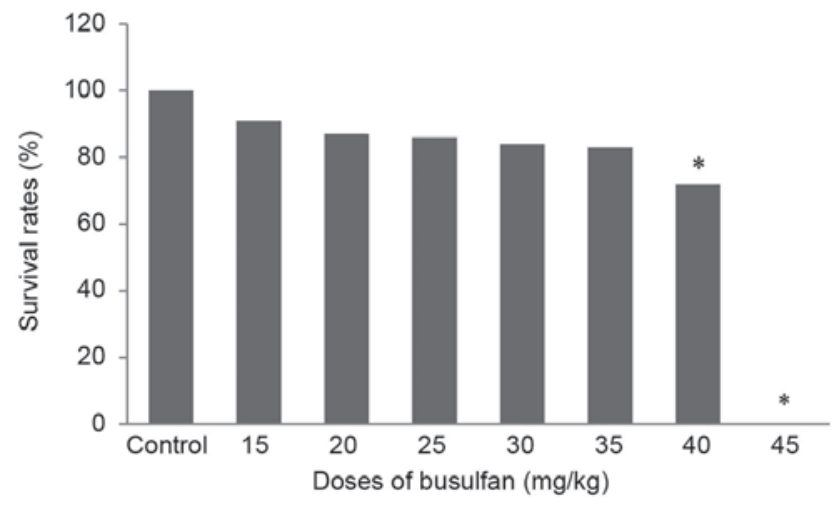

Figure 1. Survival rates of tree shrews following administration of busulfan. The survival rates of tree shrews treated with $15-35 \mathrm{mg} / \mathrm{kg}$ busulfan were not significantly affected. The $40 \mathrm{mg} / \mathrm{kg}$ group exhibited a moderate decrease in survival rate and the survival rate of $45 \mathrm{mg} / \mathrm{kg}$ group was $0 \%$. ${ }^{*} \mathrm{P}<0.05$ vs. control group.

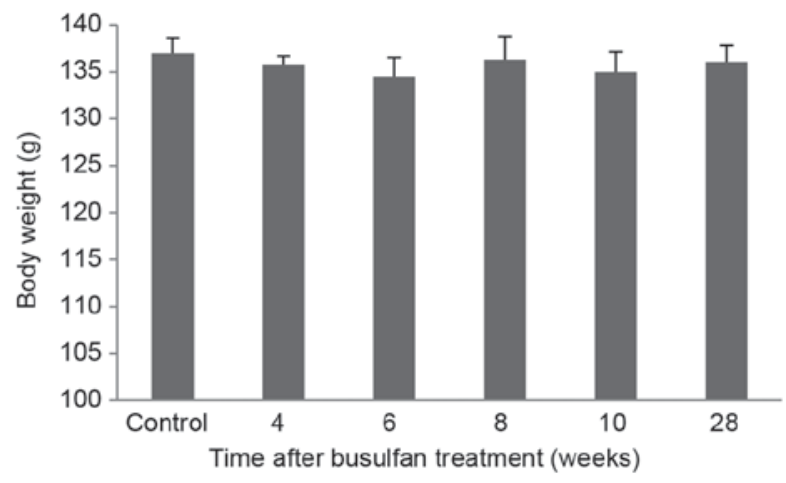

Figure 2. Changes in tree shrew body weight with time following $40 \mathrm{mg} / \mathrm{kg}$ busulfan treatment. A $40 \mathrm{mg} / \mathrm{kg}$ dose of busulfan had no significant effect on the body weight of tree shrews over the 28 week experimental period. Data are expressed as the mean \pm standard error of the mean, $n=18$ /group (accounting for mortalities induced by busulfan treatment) and $n=15 /$ group for the control group.

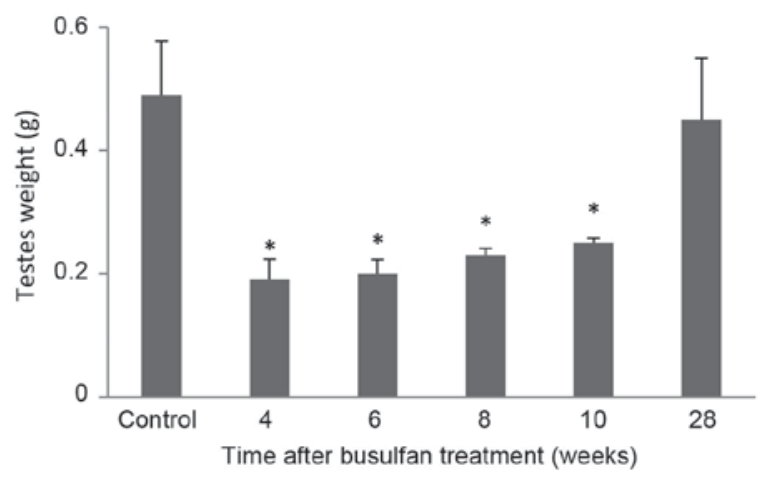

Figure 3. Reduced testicular weight induced by $40 \mathrm{mg} / \mathrm{kg}$ busulfan recovered to near control levels over time. Testes weight was significantly decreased at 4-10 weeks after treatment with $40 \mathrm{mg} / \mathrm{kg}$ busulfan, though recovered by 28 weeks post-treatment. Data are expressed as the mean \pm standard error of the mean, $n=18$ /group (accounting for mortalities induced by busulfan treatment) and $n=15 /$ group for the control group. ${ }^{*} \mathrm{P}<0.05$ vs. control group.

$\mathrm{Ab}$ tubules (Fig. 7A-C). At 6 weeks after busulfan injection, tubules in the $20 \mathrm{mg} / \mathrm{kg}$ group began to exhibit abnormal morphology without sperm, and all tubules in the $25 \mathrm{mg} / \mathrm{kg}$ 
A

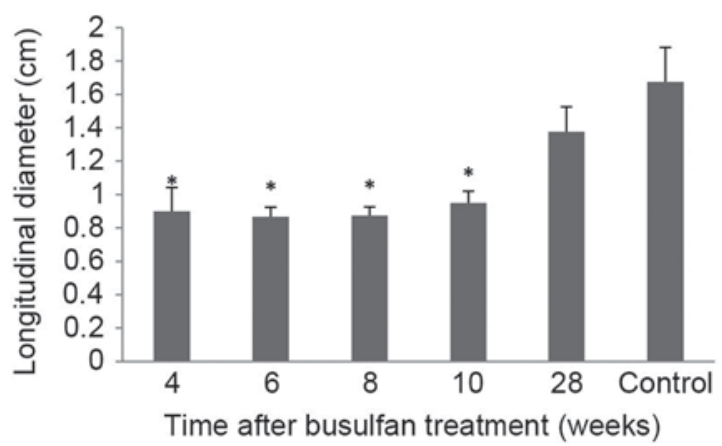

B

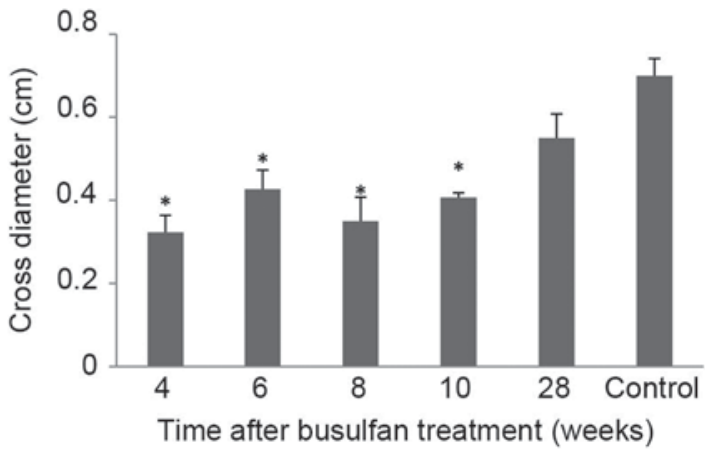

Figure 4. Reduced testicular diameters induced by $40 \mathrm{mg} / \mathrm{kg}$ busulfan recovered to near control levels over time. (A) Changes in longitudinal diameter. (B) Changes in cross diameter. Both longitudinal and cross diameters were significantly decreased at 4-10 weeks after treatment with $40 \mathrm{mg} / \mathrm{kg}$ busulfan, though recovered by 28 weeks post-treatment. Data are expressed as the mean \pm standard error of the mean, $\mathrm{n}=18$ /group (accounting for mortalities induced by busulfan treatment) and $\mathrm{n}=15 /$ group for the control group. " $\mathrm{P}<0.05$ vs. control group.

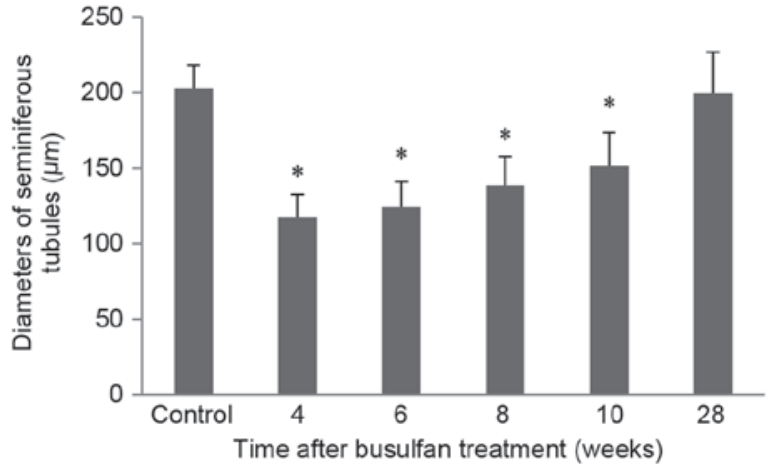

Figure 5. Diameters of the seminiferous tubules $(\mu \mathrm{m})$ in the $40 \mathrm{mg} / \mathrm{kg}$ and control groups. Seminiferous tubule diameters were significantly decreased at 4-10 weeks after treatment with $40 \mathrm{mg} / \mathrm{kg}$ busulfan, though recovered to control levels by 28 weeks. Data are expressed as the mean \pm standard error of the mean, $n=18 /$ group (accounting for mortalities induced by busulfan treatment) and $n=15 /$ group for the control group. ${ }^{*} \mathrm{P}<0.05$ vs. control group.

group were damaged, with thinner walls observed. Tubules in the $40 \mathrm{mg} / \mathrm{kg}$ group remained $\mathrm{Ab}$ (Fig. 7D-F).

Between weeks 10 and 28, tubule regeneration was observed in all treatment groups, although this occurred at later time points in the $40 \mathrm{mg} / \mathrm{kg}$ group when compared to the lower dose groups. At 10 weeks after busulfan injection, tubules in the $25 \mathrm{mg} / \mathrm{kg}$ group exhibited partial recovery and this is observed in all lower dose groups, while tubules in the $40 \mathrm{mg} / \mathrm{kg}$ group remained $\mathrm{Ab}$. However, tubules in the $40 \mathrm{mg} / \mathrm{kg}$ group also exhibited partial regeneration by 28 weeks post-treatment (Fig. 7G-I).

\section{Discussion}

Spermatogonial transplantation is used in the study of spermatogenesis and fertility, and in the production of transgenic animals. Spermatogonial transplantation is similar to hematopoietic transplantation (18), in that both methods reintroduce donor stem cells into a recipient lacking in endogenous stem cells. Similar to hematopoietic stem cells, spermatogonial stem cells divide into different sperm cell types. Due to their rapid division rate, spermatogonial stem cells are sensitive to radiation and chemotherapy, both of which target rapidly dividing cells (12), and the stem cell system may be sufficiently restored by transplanting a small number of stem cells $(5,19-23)$.

Spermatogonial transplantation has been successfully performed in numerous animal models, including mouse, rat and monkey models $(3,4,10,24,25)$. The tree shrew is widely used as a feasible animal model in medical and biological research. Thus, the present study investigated the preparation of recipient tree shrews for spermatogonial transplantation.

Preparation of recipient animals is a key step in spermatogonial transplantation. No previous studies have documented the optimal preparation of tree shrews, and thus the present study aimed to determine whether the depletion of endogenous germ cells was effective in the preparation of recipient tree shrews. In the present study, tree shrews were injected with busulfan to produce sterile recipients. Previous results have demonstrated that low doses of busulfan were insufficient in recipient animals, due to a rapid recovery in fertility and inheritance of the recipient genotype in descendants (3). However, higher doses of busulfan have been associated with increased damage in the form of thinner walls and a reduced sperm count and mortality in animals (26). Therefore, the optimal dose of busulfan dose should induce complete depletion of endogenous germ cells in the recipient while causing little harm to the testes and overall health, thus allowing restoration of spermatogenesis after spermatogonial transplantation. As the optimal dose of busulfan varies between different species, the present study aimed to identify the optimal dose of busulfan for the preparation of recipient tree shrews.

The present study demonstrated that busulfan treatment in tree shrews was an effective method of preparing recipient tree shrews for spermatogonial transplantation. In addition, the optimal dose of busulfan for the preparation of recipient tree shrews was identified over a 28 -week period. It was observed that tree shrews in the $15-35 \mathrm{mg} / \mathrm{kg}$ group had a mortality rate of $\sim 10 \%$. Meanwhile, a mortality rate of $30 \%$ was observed in the $40 \mathrm{mg} / \mathrm{kg}$ group. This was lower than the $50 \%$ mortality rate defined as the lethal dose rate for tree shrews (27). All tree shrews injected with $45 \mathrm{mg} / \mathrm{kg}$ busulfan succumbed, suggesting that the high busulfan dose exerted acute toxic effects. As tree shrews generally succumbed within the first week of busulfan treatment, their mortality was considered to be a direct result of busulfan treatment. 

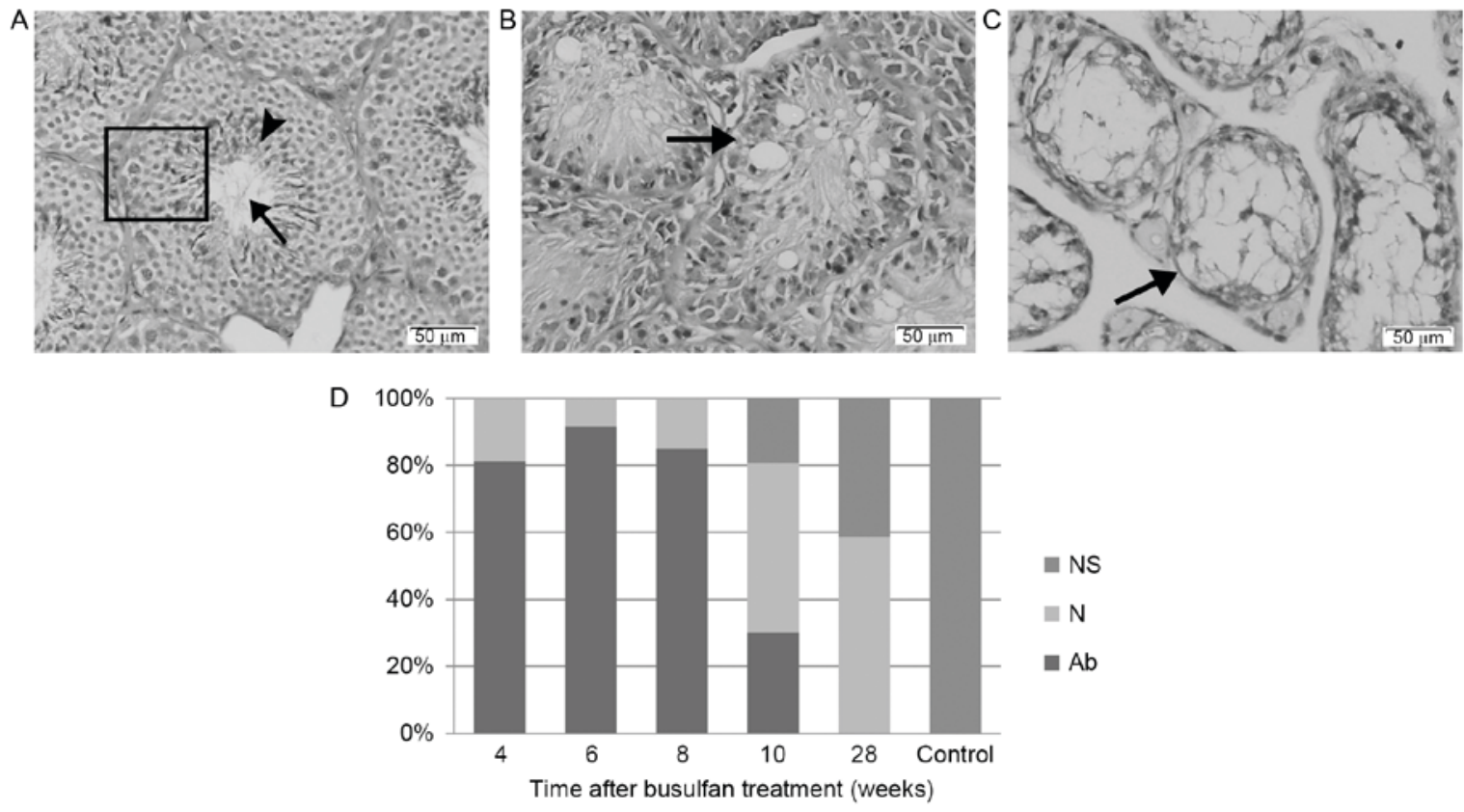

Figure 6. Histological analysis of seminiferous tubule types after $40 \mathrm{mg} / \mathrm{kg}$ busulfan treatment. (A) NS seminiferous tubules obtained from normal tree shrews in control group $(\mathrm{n}=15)$. The box indicates thickened wall, the arrowhead indicates narrow lumen, the arrow indicates spermatogenic/sertoli cells (magnification, $\mathrm{x} 20$; scale bar, $50 \mu \mathrm{m}$ ). (B) $\mathrm{N}$ seminiferous tubules obtained from tree shrews 6 weeks after treatment with $20 \mathrm{mg} / \mathrm{kg}$ busulfan (n=15). The arrow indicates the thinner tubule walls (magnification, x20; scale bar, $50 \mu \mathrm{m}$ ). (C) Ab seminiferous tubules obtained from tree shrews 4 weeks after treatment with $40 \mathrm{mg} / \mathrm{kg}$ busulfan ( $\mathrm{n}=10$ ). The arrow indicates the thinner tubule walls (magnification, $\mathrm{x} 20$; scale bar, $50 \mu \mathrm{m}$ ). (D) Percentage of tubule types in the $40 \mathrm{mg} / \mathrm{kg}$ and control groups. The change in percentage of the three tubule types indicated that the seminiferous regenerated with time after $40 \mathrm{mg} / \mathrm{kg}$ busulfan treatment. NS, normal seminiferous tubules with sperm; $\mathrm{N}$, normal seminiferous tubules without sperm; Ab, abnormal seminiferous tubules.
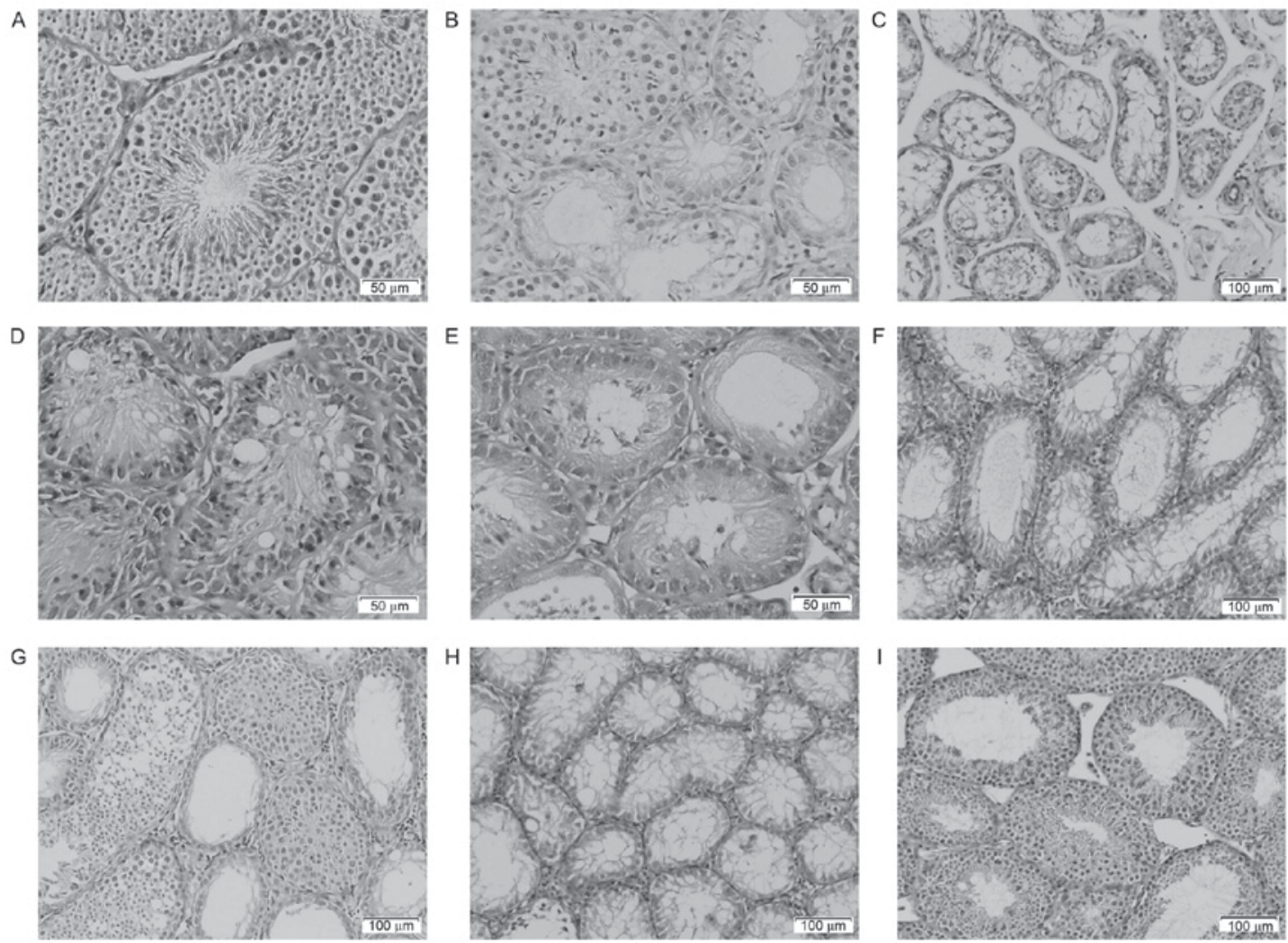

Figure 7. Comparison of spermatogenesis recovery between the different busulfan treatment groups. Representative images of the testes at 4 weeks after treatment with (A) $20 \mathrm{mg} / \mathrm{kg}(\mathrm{n}=15$; magnification, $\mathrm{x} 20$; scale bar, $50 \mu \mathrm{m})$ (B) $25 \mathrm{mg} / \mathrm{kg}(\mathrm{n}=14$; magnification, $\mathrm{x} 20$; scale bar, $50 \mu \mathrm{m})$ and (C) $40 \mathrm{mg} / \mathrm{kg}$ busulfan ( $\mathrm{n}=10$; magnification, x10; scale bar, $100 \mu \mathrm{m}$ ). Representative images of the testes at 6 weeks after treatment with (D) $20 \mathrm{mg} / \mathrm{kg}(\mathrm{n}=15 ; \mathrm{magnification}$, x20; scale bar, $50 \mu \mathrm{m}$ ), (E) $25 \mathrm{mg} / \mathrm{kg}$ (n=14; magnification, x20; scale bar, $50 \mu \mathrm{m}$ ) and (F) $40 \mathrm{mg} / \mathrm{kg}$ busulfan (n=10; magnification, x10; scale bar, $100 \mu \mathrm{m}$ ). Representative images of the testes at 10 weeks after treatment with (G) $25 \mathrm{mg} / \mathrm{kg}$ (n=14; magnification, x10; scale bar, $100 \mu \mathrm{m})$ and (H) $40 \mathrm{mg} / \mathrm{kg}$ busulfan $(\mathrm{n}=10$; magnification, $\mathrm{x} 10$; scale bar, $100 \mu \mathrm{m}$ ). (I) Representative image of the testes at 28 weeks after treatment with $40 \mathrm{mg} / \mathrm{kg}$ busulfan ( $\mathrm{n}=10$; magnification, $\mathrm{x} 10$; scale bar, $100 \mu \mathrm{m})$. Regeneration occurred later in the $40 \mathrm{mg} / \mathrm{kg}$ group relative to the lower dose groups. 
The effects of $40 \mathrm{mg} / \mathrm{kg}$ busulfan on body weight were not significant, relative to untreated controls. However, the weight and size of the testes were affected by busulfan. Notably, significant decreases were observed in the weight and size of the testes in the $40 \mathrm{mg} / \mathrm{kg}$ group up to 10 weeks after busulfan treatment, indicating that spermatogenesis had been suppressed. However, by 28 weeks, the weight and size of the testes recovered to near control levels, indicating that spermatogenesis recovered in a time-dependent manner.

Histological analysis indicated that the majority of seminiferous tubules were $\mathrm{Ab}$ in the $40 \mathrm{mg} / \mathrm{kg}$ dose group at 4-8 weeks after busulfan treatment. This indicated that within 8 weeks of the $40 \mathrm{mg} / \mathrm{kg}$ busulfan injection, restoration of spermatogenesis was limited. This indicates that treatment with $40 \mathrm{mg} / \mathrm{kg}$ busulfan may provide sufficient time for donor stem cells to successfully colonize within recipient animals. Thus, $40 \mathrm{mg} / \mathrm{kg}$ busulfan may be the optimal dose for the preparation of recipient tree shrews. At this dosage, the morality rate of tree shrews was acceptable, and a suitable microenvironment for transplantation was maintained for a sufficiently longer time period, which would allow donor germ cells to effectively colonize within recipient tree shrews.

Previous results indicate that treatment with busulfan induces only temporary and reversible damage to the testes (28). Similarly, the testes measurements and histological evaluation conducted in the current study indicated that the process of spermatogenesis had been reversibly damaged. Comparison of the different doses of busulfan also indicated that recovery of spermatogenesis was dose-dependent, as tree shrews administrated with a higher dose of busulfan $(40 \mathrm{mg} / \mathrm{kg})$ required a longer recover period. In addition, restoration of endogenous spermatogenesis in tree shrews following higher dose busulfan treatment indicated that the environment of the testes was not permanently damaged.

In conclusion, the present study demonstrated that busulfan treatment was a feasible method of preparing recipient tree shrews for spermatogonial transplantation. Combined with other transplantation techniques, busulfan administration may be a useful technique in the study of spermatogenesis and other related topics including the production of transgenic animals and male infertility therapies in tree shrew models.

\section{Acknowledgements}

The present study was supported by the Strategic Priority Research Program of the Top Talents Program of Yunnan Province China (grant no. 2012HA014), and Yunnan Applied Basic Research Projects (grant no. 2013FA020).

\section{References}

1. Olive V and Cuzin F: The spermatogonial stem cell: From basic knowledge to transgenic technology. Int J Biochem Cell Biol 37: 246-250, 2005

2. Kubota $\mathrm{H}$ and Brinster RL: Technology insight: In vitro culture of spermatogonial stem cells and their potential therapeutic uses. Nat Clin Pract Endocrinol Metab 2: 99-108, 2006.

3. Brinster RL and Avarbock MR: Germline transmission of donor haplotype following spermatogonial transplantation. Proc Natl Acad Sci USA 91: 11303-11307, 1994.

4. Brinster RL and Zimmermann JW: Spermatogenesis following male germ-cell transplantation. Proc Natl Acad Sci USA 91: 11298-11302, 1994.
5. Shinohara T, Orwig KE, Avarbock MR and Brinster RL: Remodeling of the postnatal mouse testis is accompanied by dramatic changes in stem cell number and niche accessibility. Proc Natl Acad Sci USA 98: 6186-6191, 2001.

6. Shinohara T, Orwig KE, Avarbock MR and Brinster RL: Germ line stem cell competition in postnatal mouse testes. Biol Reprod 66: 1491-1427, 2002.

7. Brinster CJ, Ryu BY, Avarbock MR, Karagenc L, Brinster RL and Orwig KE: Restoration of fertility by germ cell transplantation requires effective recipient preparation. Biol Reprod 69: 412-420, 2003.

8. Kanatsu-Shinohara M, Toyokuni S, Morimoto T, Matsui S, Honjo T and Shinohara T: Functional assessment of self-renewal activity of male germline stem cells following cytotoxic damage and serial transplantation. Biol Reprod 68: 1801-1807, 2003.

9. Moisan A, Foster R, Betteridge K and Hahnel A: Dose-response of $\mathrm{RAG}^{-1 /} / \mathrm{gammac}^{-/-}$mice to busulfan in preparation for spermatogonial transplantation. Reproduction 126: 205-216, 2003.

10. Ogawa T, Dobrinski I and Brinster R: Recipient preparation is critical for spermatogonial transplantation in the rat. Tissue Cell 31: 461-472, 1999.

11. McClive PJ and Sinclair AH: Type II and type IX collagen transcript isoforms are expressed during mouse testis development. Biol Reprod 68: 1742-1747, 2003.

12. Kim JH, Jung-Ha HS, Lee HT and Chung KS: Development of a positive method for male stem cell-mediated gene transfer in mouse and pig. Mol Reprod Dev 46: 515-526, 1997.

13. Peng YZ, Ye ZZ, Zou RJ, Wang YX, Tian BP, Ma YY and Shi LM: Biology of Chinese Tree Shrew (Tupaia belangeri chinensis). Yunnan Science and Technology Press, Kunming, China, 1991 (In Chinese with English summary).

14. Cao J, Yang EB, Su JJ, Li Y and Chow P: The tree shrews: Adjuncts and alternatives to primates as models for biomedical research. J Med Primatol 32: 123-130, 2003.

15. Schmelting B, Corbach-Söhle S, Kohlhause S, Schlumbohm C, Flügge $G$ and Fuchs E: Agomelatine in the tree shrew model of depression: Effects on stress-induced nocturnal hyperthermia and hormonal status. Eur Neuropsychopharmacol 24: 437-447, 2014.

16. Wang J, Zhou QX, Tian M, Yang YX and Xu L: Tree shrew models: A chronic social defeat model of depression and a one-trial captive conditioning model of learning and memory. Dongwuxue Yanjiu 32: 24-30, 2011.

17. Fuchs E, Flügge G, Ohl F, Lucassen P, Vollmann-Honsdorf GK and Michaelis T: Psychosocial stress, glucocorticoids, and structural alterations in the tree shrew hippocampus. Physiol Behav 73: 285-291, 2001.

18. Till JE and McCulloch EA: A direct measurement of the radiation sensitivity of normal mouse bone marrow cells. Radiat Res 14: 213-222, 1961.

19. Potten CS, Schofield R and Lajtha LG: A comparison of cell replacement in bone marrow, testis and three regions of surface epithelium. Biochim Biophys Acta 560: 281-299, 1979.

20. Potten CS: Cell lineages. In: Oxford Textbook of Pathology. McGee JO, Isaacson PG, Wright NA (eds). Vol 1. Oxford University Press, pp43-52, 1992.

21. Osawa M, Hanada K, Hamada $\mathrm{H}$ and Nakauchi H: Long-term lymphohematopoietic reconstitution by a single CD34-low/negative hematopoietic stem cell. Science 273: 242-255, 1996.

22. Ogawa T, Dobrinski I, Avarbock MR and Brinster RL: Transplantation of male germ line stem cells restores fertility in infertile mice. Nat Med 6: 29-34, 2000.

23. Copelan EA: Hematopoietic stem-cell transplantation. N Engl J Med 354: 1813-1826, 2006.

24. Schlatt S, Foppiani L, Rolf C, Weinbauer G and Nieschlag E: Germ cell transplantation into X-irradiated monkey testes. Hum Reprod 17: 55-62, 2002.

25. Honaramooz A, Behboodi E, Megee SO, Overton SA, Galantino-Homer H, Echelard Y and Dobrinski I: Fertility and germline transmission of donor haplotype following germ cell transplantation in immunocompetent goats. Biol Reprod 69: 1260-1264, 2003.

26. Bucci L and Meistrich M: Effects of busulfan on murine spermatogenesis: Cytotoxicity, sterility, sperm abnormalities, and dominant lethal mutations. Mutat Res 176: 259-268, 1987.

27. Wang DZ, Zhou XH, Yuan YL and Zheng XM: Optimal dose of busulfan for depleting testicular germ cells of recipient mice before spermatogonial transplantation. Asian J Androl 12: 263-270, 2010.

28. Karashima T, Zalatnai A and Schally AV: Protective effects of analogs of luteinizing hormone-releasing hormone against chemotherapy-induced testicular damage in rats. Proc Natl Acad Sci USA 85: 2329-2333, 1988. 